\title{
Determination of the mean cross-sectional area of the thoracic aorta using a double indicator dilution technique
}

Received: 2 February 1996/Received after revision: 10 May 1996/Accepted: 6 June 1996

\begin{abstract}
A double indicator dilution technique for determining the mean cross-sectional area (CSA) of a blood vessel in vivo is presented. Analogous to the thermodilution method, dilution of hypertonic saline was measured by an electrical conductance technique. Because the change in conductance rather than absolute conductance was used to calculate CSA, pulsatile changes in shear rate of blood and conductance of surrounding tissues had no effect on the data. To calculate CSA from an ion mass balance, cardiac output was needed and estimated from the thermodilution curve using the same "cold" (hypertonic) saline injection. The mean CSA, obtained from this double indicator dilution method $\left(\mathrm{CSA}_{\mathrm{GD}}\right)$, was compared with the CSA obtained from the intravascular ultrasound method (IVUS) in 44 paired observations in six piglets. The regression line is close to the line of identity $\left(\mathrm{CSA}_{\mathrm{GD}}=-1.83+1.06 \cdot \mathrm{CSA}_{\mathrm{IV} U S}, r=0.96\right)$. The difference between both CSAs was independent of the diameter of the vessel, on average $-0.99 \mathrm{~mm}^{2} \pm$ $2.64 \mathrm{~mm}^{2}$ (mean $\mathrm{CSA}_{\mathrm{GD}}=46.84 \pm 8.21 \mathrm{~mm}^{2}$, mean $\mathrm{CSA}_{\text {Ivus }}=47.82 \pm 9.08 \mathrm{~mm}^{2}$ ) and not significant. The results show that the double indicator dilution method is a reliable technique for estimating the CSA of blood vessels in vivo.
\end{abstract}

Key words Arteries - Conductivity · Conductance method . Double indicator dilution method. Shear rate $\cdot$ Intravascular ultrasound

L. Kornet $\cdot$ J.R.C. Jansen $(X) \cdot A$. Versprille

Pathophysiological Laboratory, Department of Pulmonary Diseases, Pathophysiological laboratory, Erasmus University, P.O. Box 1738, 3000-DR, Rotterdam, The Netherlands

E.J. Gussenhoven

The Interuniversity Cardiology Institute, Erasmus Univeristy, Rotterdam, The Netherlands

\section{Introduction}

Several methods for determining the cross-sectional (CSA) area of blood vessels are available. Mechanical devices include a strain-gauge caliper [15], a device which moves a metal core in a coil to change the inductance of the coil [18], and ultrasonic distance crystals $[5,7,11,13,18,19,24-26]$. They have the disadvantage of introducing a restraint on the vessel wall. Devices which do not affect the vessel wall are a photoelectrical apparatus, used only in vitro [21], X-ray angiography $[2,6,14,16,22]$, intravascular ultrasound (IVUS) $[29,30]$ and ultrasound wall-tracking techniques [8]. Angiography, IVUS and ultrasound walltracking techniques are expensive and the first two require labour-intensive analyses. Ultrasound walltracking techniques determine only the diameter of a blood vessel, instead of the whole cross-section. Furthermore, the angle of the ultrasound beam should be $90^{\circ}$ to determine the diameter of a blood vessel.

We have developed a new method for determining the mean CSA of a blood vessel without affecting the vessel wall. The method presents CSA on-line and thus does not require labour-intensive, off-line analyses and is relatively inexpensive. The CSA obtained using the double indicator dilution method ("cold" and ions), was compared with the CSA obtained using IVUS.

\section{Materials and methods}

Ion mass balance for calculation of mean CSA

If a hypertonic saline solution is injected upstream, a change in conductance is detected downstream in the blood circulation (dilution of ions). The conductivity balance is based on the assumption that the amount of ions conducting an electrical current is the same at the injection and detection site. The injectate (at room temperature) is heated by the blood after injection, increasing the conductivity of the injectate. The conductivity of the injectate is thus corrected for blood temperature. Assuming complete mixing of indicator and 
blood, the following conductivity balance can be written:

$\int_{t_{1}}^{t_{2}} \dot{Q}_{\mathrm{i}}(t)\left[\sigma_{\mathrm{i}}-\sigma_{\mathrm{b}}\right] \mathrm{d} t=\int_{t_{1}}^{t_{2}} \Delta \sigma_{\mathrm{b}}(t) \dot{Q}_{\mathrm{b}}(t) \mathrm{d} t$

where $t$ is time; $t_{1}$ the time of injection, $t_{2}$ the end of the integration period when all injected ions have passed the detector site, $\dot{Q}_{i}$ the input flow of the injectate, $\sigma_{i}$ the electrical conductivity of the injectate at blood temperature, $\sigma_{\mathrm{b}}$ the conductivity of the blood before injection, $\Delta \sigma_{b}$ the change in conductivity of the blood due to the injection of the hypertonic saline and $\dot{Q}_{\mathrm{b}}$ the mean blood flow at the position where CSA is determined. If the injection is fast and $\dot{Q}_{\mathrm{b}}(t)$ is constant the equation can be rewritten as:

$Q_{\mathrm{i}}\left(\sigma_{\mathrm{i}}-\sigma_{\mathrm{b}}\right)=\dot{Q}_{\mathrm{b}} \int_{t_{1}}^{t_{2}} \Delta \sigma_{\mathrm{b}}(t) \mathrm{d} t$

where $Q_{\mathrm{i}}$ is the volume of the injectate. The change in conductivity of blood $\left(\Delta \sigma_{b}\right)$ could not be determined directly in these experiments, instead conductance $(G)$ was determined at the site where CSA is determined using a conductance catheter [3]. The conductance catheter is constructed with four electrodes equidistantly $(5 \mathrm{~mm})$ placed at its distal end. An alternating current of $70 \mu \mathrm{A}$ (RMS) and $20 \mathrm{kHz}$ is applied to the two outer electrodes (model Sigma 5, Leycom, Cardiodynamics, Rijnsburg, The Netherlands). The induced voltage between the two inner electrodes is measured. An offset is caused by the conductance of the surrounding tissues, which is called parallel conductance $\left(G_{p}\right)[3]$. The time-varying conductance $\left(G_{(1)}\right)$ measured by the conductance catheter is related to the time-varying cross-sectional area $\left[\operatorname{CSA}_{\mathrm{GD}}(t)\right]$ by the relationship:

$G(t)=\frac{\mathrm{CSA}_{\mathrm{GD}}(t) \times \sigma_{\mathrm{b}}(t)}{L}+G_{\mathrm{p}}(t)$

where $L$ is the distance between the electrodes. If the mean $G_{\mathrm{p}}$ over each heart cycle is constant during the injection of the hypertonic saline, the change in conductivity can be rewritten as:

$\Delta \sigma_{\mathrm{b}}(t)=\frac{L \times \Delta G(t)}{\operatorname{CSA}_{\mathrm{GD}}(t)}$

Substituting $\Delta \sigma_{\mathrm{b}}(t)$ in Eq. 2 gives:

$\mathrm{Q}_{\mathrm{i}}\left(\sigma_{\mathrm{i}}-\sigma_{\mathrm{b}}\right)=\frac{\dot{Q}_{\mathrm{b}} \times L}{\mathrm{CSA}_{\mathrm{GD}}(t)} \int_{t_{1}}^{t_{2}} \Delta G(t) \mathrm{d} t$

If measured at steady-state conditions, as during an inspiratory pause procedure (IPP), CSA averaged over a heart cycle will not change. An IPP is a procedure in which a tidal volume is inflated and held in the lungs for several seconds, followed by an expiration [28]. During the IPP, arterial pressure and left ventricular output remain constant from $1-2 \mathrm{~s}$ after the start of the pause period. Furthermore, in previous work (unpublished data, L. Komet, J.R.C. Jansen, E.J. Gussenhoven, M.R. Hardeman, A. Versprille) we found no influence of injectate on vessel volume. Therefore, mean CSA during a heart cycle will remain constant after an injection of indicator given during the IPP, and Eq. 5 can be rewritten as:

$\mathrm{CSA}_{\mathrm{GD}}=\frac{\dot{Q}_{\mathrm{b}} \times L}{Q_{\mathrm{i}}\left(\sigma_{\mathrm{i}}-\sigma_{\mathrm{b}}\right)} \int_{t_{1}}^{t_{2}} \Delta G(t) \mathrm{d} t$

In our experiments $\sigma_{\mathrm{b}}$ is a factor of 25 lower than $\sigma_{\mathrm{i}}(\mathrm{NaCl}$ injectate $=3 \mathrm{M}$ ) and can be neglected, giving:

$\mathrm{CSA}_{\mathrm{GD}}=\frac{\dot{Q}_{\mathrm{b}} \times L}{Q_{\mathrm{i}} \times \sigma_{\mathrm{i}}} \int_{i_{1}}^{t_{2}} \Delta G(t) \mathrm{d} t$

We injected cold hypertonic saline into the right atrium and determined the CSA in the thoracic aorta. The assumption that the amount of injected ions equals the amount of detected ions is incorrect, because a part of the injected solution might have entered open side-branches such as the branchiocephalic trunk and the left subclavian and carotid arteries. By "open" we mean that the flow of the side-branch does not re-enter the main branch upstream from the site where the CSA is determined. If complete mixing of indi- cator with blood occurs, the amount of injected ions $\left(Q_{i} \cdot \sigma_{i}\right)$ will be distributed in each branch in proportion to flow [31]. Thus, the amount of ions passing the detection site should be multiplied by the flow at the detection site $\left(\dot{Q}_{b}\right)$ divided by the total cardiac output before branching $\left(\dot{Q}_{\mathrm{T}}\right)$, giving:

$\mathrm{CSA}_{\mathrm{GD}}=\frac{\dot{Q}_{\mathrm{b}} \times L}{\frac{\dot{Q}_{\mathrm{b}}}{\dot{Q}_{\mathrm{T}}} \mathrm{Q}_{\mathrm{i}} \times \sigma_{\mathrm{i}}} \int_{t_{1}}^{t_{2}} \Delta G(t) \mathrm{d} t$

Equation 8 can be rewritten as:

$\mathrm{CSA}_{\mathrm{GD}}=\frac{\dot{Q}_{\mathrm{T}} \times L}{Q_{\mathrm{i}} \times \sigma_{\mathrm{i}}} \int_{t_{1}}^{t_{2}} \Delta G(t) \mathrm{d} t$

These equations imply that the fraction of cardiac output and the fraction of injected ions passing the detection site are equal. Conductance, determined after injection of the (cold) hypertonic saline, was averaged for each heart cycle and plotted versus time. A baseline was drawn from the start $\left(t_{1}\right)$ to the end of the dilution curve $\left(t_{2}\right)$. The area under the baseline was subtracted from the area under the total dilution curve to obtain the area under the dilution curve [ $\Delta G(t)]$, which is corrected for accumulation of salt in the vessel wall and recirculation. $L, Q_{\mathrm{i}}$ and $\sigma_{\mathrm{i}}$ are known. $\dot{Q}_{\mathrm{T}}$ is determined using the thermodilution method, which is based on the law of conservation of thermal energy $[9,23,31]$. Therefore, the change in temperature is processed after injection of a known amount of cold hypertonic saline, which is the same injection as used to induce a change in conductance. For practical reasons we determined cardiac output in the pulmonary artery. It would also be possible to determine the temperature signal in the thoracic aorta, because the change in temperature of the blood, due to the injectation of the cold injectate, will be equal before and after branching.

Intravascular ultrasound

To evaluate the determination of CSAs with the use of the dilution signals of conductance and temperature, the results were compared with those of intravascular ultrasound (IVUS) (DuMed, Rotterdam, The Netherlands). This method is based on a $32 \mathrm{MHz}$ single-element transducer mounted on the tip of a flexible driveshaft, which rotates inside a $5 \mathrm{~F}$ catheter. Cross-sectional images with $512 \cdot 512$ pixels and 256 grey levels were scanned at a speed of 25 images/s. Axial resolution of the system was better than $0.1 \mathrm{~mm}$ and the maximum scan depth was $9 \mathrm{~mm}$. CSAs with a diameter larger than $9 \mathrm{~mm}$ were excluded, because the IVUS catheter was positioned against the vessel-wall, as visualised by the method itself and radiographic imaging. Blood pressure and time were displayed simultaneously on a video screen. Ultrasound images were analysed off-line for free lumen-area determination using a computerized analytical system [29, 30].

Surgical procedures and ventilatory conditions

All experiments were performed in accordance with the Guide for Care and Use of Laboratory Animals published by the US National Institute of Health [NIH publication No. 85-23, Revised 1985] and in accordance with the regulations of the Animal Care Committee of the Erasmus University Rotterdam, The Netherlands.

Six piglets ( $5-7$ weeks old, $9.3 \pm 0.9 \mathrm{~kg}$ body weight) were anaesthetized with an intraperitoneal injection of pentobarbitone sodium (30 $\mathrm{mg} \cdot \mathrm{kg}^{-1}$ bodyweight). The animals were placed in a supine position on a thermo-controlled operating table to maintain body temperature at about $38.5^{\circ} \mathrm{C}$. Anaesthesia was maintained by a continuous infusion of pentobarbitone sodium $\left(8.5 \mathrm{mg} \cdot \mathrm{h}^{-1} \cdot \mathrm{kg}^{-1}\right)$ via an ear vein. Electrocardiogram (ECG) electrodes were placed on the right leg and on the chest of the pig near the xyphoid cartilage. After tracheostomy, the pigs were connected to a volume- 
controlled ventilator [10] and ventilated with ambient air against a positive end-expiratory pressure of $2 \mathrm{~cm} \mathrm{H}_{2} \mathrm{O}$. The ventilatory frequency was 10 breaths $\backslash$ min. Tidal volume was adjusted to a $P_{a, C_{2}}$ of $38-45 \mathrm{mmHg}$ during baseline.

A conductance catheter was inserted through the carotid artery into the descending thoracic aorta to detect the saline conductance dilution curve. The lumen of the conductance catheter was used for measuring arterial pressure and sampling blood. From the opposite direction, an ultrasound imaging catheter was inserted through the femoral artery. The distal ends of both catheters were situated close to each other under radiographic guidance. We thus regarded both catheters to be measuring the same CSA. Through the external jugular vein a Swan-Ganz catheter (5F) was inserted to detect the temperature dilution curve and pressure within the pulmonary artery. In addition, a four-lumen catheter was inserted through the jugular vein into the superior vena cava to measure central venous pressure and to infuse anaesthetic and pancuronium. A third catheter was inserted through the jugular vein into the atrium to inject the cold hypertonic saline.

To avoid clotting, the three pressure catheters were continuously flushed at a flow rate of $3 \mathrm{ml} \cdot \mathrm{h}^{-1}$ with saline $(0.9 \% \mathrm{NaCl})$, containing $10 \mathrm{IU} / \mathrm{ml}$ heparin. A catheter was placed into the bladder to prevent retention of urine. After surgery, pancuronium bromide $\left(0.3 \mathrm{mg} \cdot \mathrm{h}^{-1} \cdot \mathrm{kg}^{-1}\right.$, after a loading dose of $\left.0.2 \mathrm{mg} \cdot \mathrm{kg}^{-1}\right)$ was infused to suppress spontaneous breathing. The pentobarbitone sodium infusion was switched from the ear vein to the superior vena cava. The surgical procedures were followed by a stabilization period of about $30 \mathrm{~min}$.

\section{Experimental protocol}

CSA was changed by changing aortic pressure. Various levels of arterial pressure were created by IPPs in between normal ventilations [28]. Between each IPP there was a stabilisation period of $15 \mathrm{~min}$. The IPPs were characterized by an inflation time of $2.4 \mathrm{~s}$, an inspiratory pause of $15 \mathrm{~s}$, followed by an expiration of $3.6 \mathrm{~s}$. A series of IPPs consisted of a stepwise increase in inflation volume with $5 \mathrm{ml} / \mathrm{kg}$ body weight. The series was ended if the aortic pressure reached a critical level of approximately $40 \mathrm{~mm} \mathrm{Hg}$ during the IPP. At $6.3 \mathrm{~s}$ after the beginning of an IPP, a hypertonic cold solution $(2.5 \mathrm{ml} 3 \mathrm{M} \mathrm{NaCl}$ at room temperature) was injected. During the IPPs, pressures, ECG, temperature and the conductance signal were stored on disk for analyses at a sample frequency of $250 \mathrm{~Hz}$. The intravascular ultrasound images were recorded simultaneously on videotape with the pressure and time signals.
Calculations

For every measurement, the mean CSA, obtained with the double indicator dilution method during the passage of the temperature and conductance dilution curve, was compared with the CSA derived from the mean of all IVUS images (more than 100), obtained within the same period. Mean values are given $\pm \mathrm{SD}$.

\section{Results}

The relationship between the intravascular CSA determined with the double indicator dilution method,

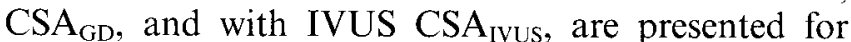
six piglets $(n=44)$ in Fig. 1A. The regression line is close to the line of identity $\left(\mathrm{CSA}_{\mathrm{GD}}=-1.83+\right.$ $\left.1.06 \cdot \mathrm{CSA}_{\mathrm{IVUS}}\right), r=0.96$. In a Bland-Altman scatter diagram [1], the differences between the two CSAs were plotted against the mean CSAs obtained using both methods (Fig. 1B). The difference was independent of the diameter of the vessel. The difference was on average $-0.99 \mathrm{~mm}^{2} \pm 2.64 \mathrm{~mm}^{2}$, (mean $\mathrm{CSA}_{\mathrm{GD}}=46.84 \pm$ $8.21 \mathrm{~mm}^{2}$, mean $\mathrm{CSA}_{\mathrm{IVUS}}=47.82 \pm 9.08 \mathrm{~mm}^{2}$ ) and not significant.

\section{Discussion}

A new, cheap, simple and non-labour intensive method for determining the mean CSA of the thoracic aorta on-line was evaluated. This double indicator dilution method presumably can also be used to determine CSAs of other arteries in vivo.

Arterial pressure is routinely determined in patients undergoing intensive care, cardio-thoracic surgery or catheterization for diagnostic reasons. In the patients, undergoing catheterization for diagnostic reasons, a pressure catheter is normally present in the aorta.
Fig. 1A Correlation between the average results of vessel cross-sectional area $(C S A)$ determination by $\left(C S A_{G D}\right)$ and intravascular ultrasound (IVUS), (CSA $\left.A_{I V U S}\right)$. The best linear fit is given by dashed line. The line of identity is indicated as the solid line. B Scatter diagram of the differences between the $\mathrm{CSA}_{\mathrm{GD}}$ values obtained with the double indicator dilution method and those with IVUS, as a function of the mean CSA of both methods. The solid line indicates the mean difference and the dashed lines indicate the $95 \%$ confidence interval (2SD)
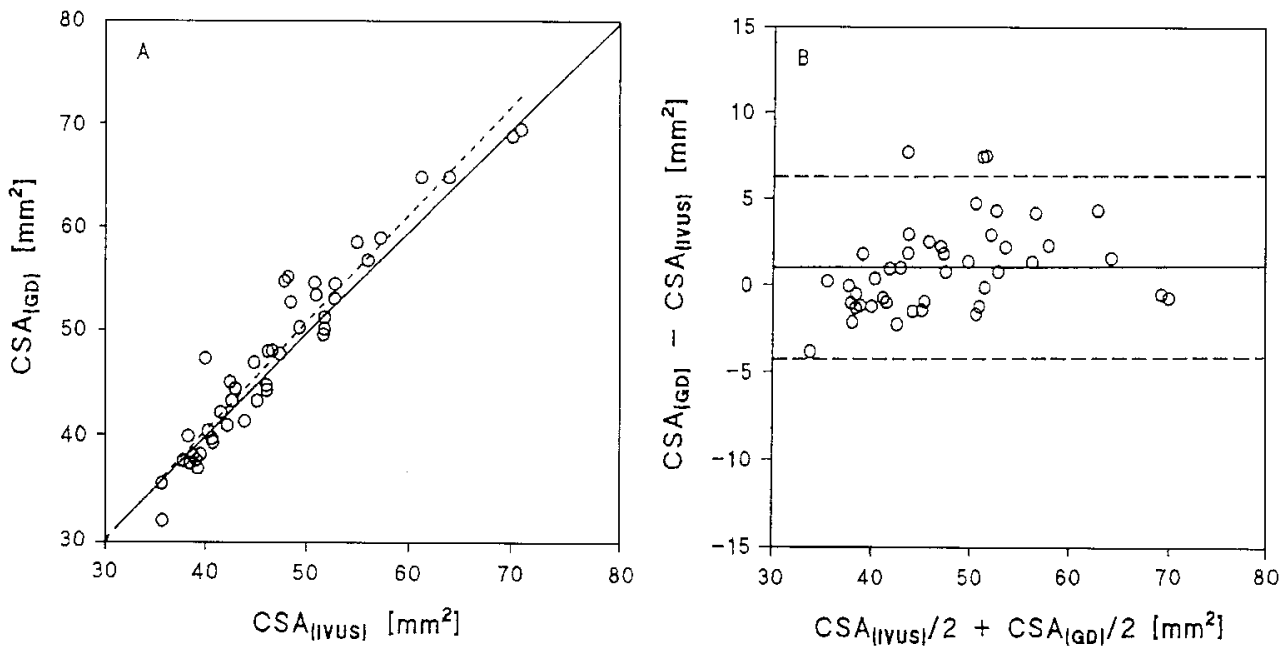
During intensive care and cardio-thoracic surgery, arterial pressure is determined in both the pulmonary and femoral or radial arteries, using a pulmonary arterial catheter (PAC) and a radial or femoral arterial catheter respectively. These catheters and the aortic catheter can be equipped easily with four electrodes to determine the dilution of ions. The dilution of temperature can be determined with use of a thermistor, which also can be mounted at the tip of an aortic, radial or femoral catheter and is routinely mounted at the tip of the PAC. The cold hypertonic saline can be injected into the right atrium, using the injection lumen of the PAC. In our experience with such a catheter the pulmonary artery can be catheterized.

Determination of arterial CSA in these patients can be used to monitor the effect of drug therapy on CSA and compliance in the operating room, without the need for expensive and labour intensive ultrasound methods. Furthermore, obstructions and aneurysms can possibly be detected by moving the catheter in the longitudinal direction through the vessel.

\section{Parameters influencing conductance}

Prior to this study, electrical conductance has not been used to determine the volume of a large blood vessel as has been done for the ventricular volume [3], because of a pulsatile flow and thus pulsatile change in shear rate in blood vessels. A pulsatile shear rate will cause a pulsatile orientation and deformation of erythrocytes which, in turn, will cause a pulsatile change in blood conductivity [17]. In the ventricle, non-uni directional flow causes no unidirectional orientation and deformation of erythrocytes. To determine the CSA (i.e. segmental volume) of a blood vessel using the conductance signal, the conductivity has to be corrected continuously for shear rate, heart rate and the time constants of (de)orientation, (de)formation and (de)aggregation of the erythrocytes. In the present study, the problem of pulsatile changes in the conductivity of blood is eliminated by the use of the double indicator dilution method which does not employ the absolute conductivity of blood but rather the change in blood conductivity, and thus the change in conductance, after the injection of cold hypertonic saline, to determine CSA. During passage of the salt ions as a dilution curve, the amount of erythrocytes and their behaviour did not change. Thus, the change in conductance was not affected by shear rate.

The effect of the cold injectate on conductivity of blood by changing blood temperature could be neglected. A fall in blood temperature from 38.5 to $38^{\circ} \mathrm{C}$ at a haematocrit of $30 \%$, due to the injection of a cold solution, will decrease blood conductivity only $0.3 \%$.

The quantity of total injected salt in our piglets was about $400 \mathrm{mg} / \mathrm{kg}$, which was below that used thera- peutically in case of a hypovolaemic shock $[12,27]$ and must therefore be considered harmless. We did not observe any negative effects on haemodynamic conditions. In medical practice we expect that the amount of injected salt ions related to body weight will be lower than in these experiments, because cardiac output per body weight is lower and series of IPPs will not be necessary.

\section{Evaluation of the double indicator dilution method}

With the IVUS the CSA is determined at one position in a vessel, whereas with the double indicator dilution method a mean CSA between the measuring electrodes is determined. We assume that this difference causes a very small bias in the results [4], because both probes were located close to each other in the descending aorta. It should be noted that the difference between the IVUS and the double indicator dilution method may be related to the error caused by inter-observer variation of the IVUS. The intra-observer variation of the IVUS [30] could be neglected, because one data point was the mean of more than 100 images, measured during passage of the dilution curve. The difference between the CSAs obtained with the double indicator dilution method and the IVUS was not significant. Based on our results we conclude that the double indicator dilution method is a reliable technique for estimating CSA in blood vessels.

Acknowledgements The authors thank Mr. A. Drop, Mr. J. Honkoop and Mr. M. van Oosterhout for their technical assistance.

\section{References}

1. Altman DG (1990) Practical statistics for medical research. Chapman and Hall, London, pp 397-399

2. Arndt JO, Stegall HF, Wicke HJ (1971) Mechanics of the aorta in vivo. A radiographic approach. Circ Res 28:693-704

3. Baan J, Velde ET van der, Bruin HG de, Smeenk GJ, Koops J, Dijk AD van, Temmerman D, Senden PJ, Buis B (1984) Continuous measurement of left ventricular volume in animals and humans by conductance catheter. Circulation 70:812-823

4. Caro CG, Pedley TJ, Schroter RC, Seed WA (1978) The mechanics of the circulation. Oxford University Press, Oxford, p 48

5. Gentile BJ, Chuong CJC, Ordway GA (1988) Regional volume distensibility of canine thoracic aorta during moderate treadmill exercise. Circ Res 63:1012-1019

6. Gozna ER, Marble AE, Shaw A, Holland JG (1974) Agerelated changes in the mechanics of the aorta and pulmonary artery of man. J Appl Physiol 36:407-411

7. Gross DR, Hunter JF, Allert JA, Hwang NH, Patel DJ (1981) Pressure-diameter relationship in the coronary of intact, awake calves. J Biomech 14:613-620

8. Hoeks APG, Brands PJ, Smeets FAM, Reneman RS (1990) Assessment of the distensibility of superficial arteries. Ultrasound Med Biol 16:121-128

9. Jansen JRC (1995) The thermodilution method for the clinical assessment of cardiac output. Intensive Care Med 21:691-697 
10. Jansen JRC, Hoorn E, Goudoever J van, Versprille A (1989) A computerized respiratory system including test functions of lung and circulation. J Appl Physiol 67:1687-1691

11. Johnson TA, Henry GW, Lucas CL, Keagy BA, Lores ME, Hsiao HS, Ferreiro JI, Wilcox BR (1985) Two-dimensional in vivo pressure/diameter relationships in the canine main pulmonary artery. Cardiovasc Res 19:442-448

12. Kien ND, Kramer GC (1989) Cardiac performance following hypertonic saline. Braz J Med Biol Res 22:245-248

13. Latson TW, Hunter WC, Katoh N, Sagawa K (1988) Effect of nitroglycerin on aortic impedance, diameter, and pulse-wave velocity. Circ Res 62:884 -890

14. Leitz KH, Arndt JO (1968) Die Durchmesser-Druck-Beziehung des intakten Gefässgebietes der Arterie carotis communis von Katzen. Pflügers Arch $301: 50 \quad 69$

15. Mallos AJ (1962) An electrical caliper for continuous measurement of relative displacement. J Appl Physiol 17:131 134

16. Merillon JP, Motte G, Fruchaud J, Masquet C, Gourgon RC (1978) Evaluation of the elasticity and characteristic impedance of the ascending aorta in man. Cardio vasc Res 12:401-406

17. Nakajima T, Kon K, Maeda N, Tsunekawa K, Shiga T (1990) Deformation response of red blood cells in oscillatory shear flow. Am J Physiol 259: H1071-H1078

18. Pagani M, Schwartz PJ, Bishop VS, Malliani A (1975) Reflux sympathetic changes in aortic diastolic pressure-diameter relationship. Am J Physiol 229:286 290

19. Pagani M, Baig H, Sherman A. Manders WT, Quinn P, Patrick T, Franklin D, Vatner SF (1978) Measurement of multiple simultaneous small dimensions and study of arterial pressuredimension relations in conscious animals. Am J Physiol 235: H610-H617

20. Peterson LH, Jensen RE, Parnell J (1960) Mechanical properties of arteries in vivo. Circ Res 8:622-639

21. Schabert A, Bauer RD, Busse R (1980) Photoelectric device for the recording of diameter changes of opaque and transparent blood vessels in vitro. Pflügers Archiv 385:239-242
22. Stefanadis C, Wooley CF, Bush CA. Kolibash AJ, Boudoulas $\mathrm{H}$ (1987) Aortic distensibility abnormalities in coronary artery disease. Am J Cardiol 59:1300-1304

23. Stewart GN (1921) The output of the heart in dogs. Am J Physiol 57:27-50

24. Tomoike H, Ootsubo H, Sakai K, Kichuchi Y, Nakamura M (1981) Continuous measurement of coronary artery diameter in situ. Am J Physiol 240:H73-H79

25. Vatner SF, Hintze TH (1982) Effects of a calcium channel antagonist on large and small coronary arteries in conscious dogs. Circulation 66:579-588

26. Vatner SF, Pagani M, Manders WT, Pasipoularides AD (1980) Alpha-adrenergic vasoconstriction and nitroglycerin vasodilation of large coronary arteries in the conscious dog. J Clin Invest $65: 5-14$

27. Velasco IT, Pontieri V, Rocha- e- = Silva MJr, Lopes OU (1980) Hyperosmotic $\mathrm{NaCl}$ and severe haemorrhagic shock. Am J Physiol 239: H664-H673

28. Versprille A, Jansen JRC (1985) Mean systemic filling pressure as a characteristic pressure for venous return. Pflügers Archiv $405: 226-233$

29. Wenguang L, Gussenhoven WJ, Bosch JG, Mastik F, Reiber JHC, Bom N (1990) A computer-aided analysis system for the quantitative assessment of intravascular ultrasound images. Computers in cardiology pp 333-336

30. Wenguang L, Gussenhoven WJ, Zhong Y, The SHK, Di Mario C, Madretsma S, Egmond $F$ van. Feyter $F$ de, Pieterman $H$, Urk H van, Rijsterborgh H, Bom N (1991) Validation of quantitative analysis of intra-vascular ultrasound images. Int J Card Imaging 6:247-253

31. Zierler KL (1962) Theoretical basis of indicator dilution methods for measuring flow and volume. Circ Res 10:393-407 